\title{
Mckittrick-Wheelock Syndrome and Diabetes Insipidus
}

\author{
Swissa $\mathrm{M}^{{ }^{1}}$, Teodorovich $\mathrm{N}^{1}$, Shaked $\mathrm{Y}^{2}$ and Garty $\mathrm{M}^{2}$ \\ ${ }^{1}$ Heart Institute, Kaplan Medical center, Rehovot, Hebrew University School of Medicine, Jerusalem, Israel \\ ${ }^{2}$ Department of Medicine, Rabin Medical Center, Petah Tiqva, and Sackler Faculty of Medicine, Tel Aviv University, \\ Tel Aviv, Israel
}

${ }^{*}$ Corresponding author: Swissa M, M.D., Heart Institute, Kaplan Medical Center, Rehovot, Hebrew University School of Medicine, Jerusalem, P O Box 1, Rehovot, Israel 76100, Fax: 08-9441590, Tel: 08-9441376, 0508573523, E-mail: swissam@clalit.org.il

Citation: Swissa M, Teodorovich N, Shaked Y, Garty M (2015) Mckittrick-Wheelock Syndrome and Diabetes Insipidus. J Case Rep Stud 3(5): 502. doi: 10.15744/2348-9820.3.502

Received Date: June 09, 2015 Accepted Date: October 09, 2015 Published Date: October 12, 2015

\begin{abstract}
Secretory villous adenoma is characterized with watery diarrhea, which may lead to dehydration, with resulting volume depletion, electrolyte imbalance, circulatory failure and renal dysfunction. We hereby report a case of villous adenoma associated with severe electrolyte imbalance complicated by diabetes insipidus. Successful management is available by strict preoperative monitoring and surgical resection of the tumor. The pathophysiology of this syndrome and the therapeutic implications are reviewed.
\end{abstract}

Keywords: Villous adenoma; Hyperkalemia; Depletion Syndrome

\section{Case Report}

A sixty-one year old woman was admitted with a one-month history of weakness, confusion and a $5 \mathrm{~kg}$ weight loss. On examination she had 30 breaths per minute and was dehydrated. The blood pressure was 110/70 mmHg. Neurological examination indicated mild confusional state. The abdomen was soft and non-tender. No masses were felt on palpation or rectal examination. The patient's blood count and biochemistry on presentation is shown in Table 1. A chest and abdominal X-ray were normal. On ECG a prolonged QT interval (mostly due to prolonged ST segment) of $0.56 \mathrm{sec}$ was noted due to severe hypocalcemia (5.9 mg/dL). The severe dehydration state and extreme hypokalemia $(1.8 \mathrm{mEq} / \mathrm{L})$, hypomagnesemia $(0.9 \mathrm{mg} / \mathrm{dL})$ and hyponatremia $(106 \mathrm{mEq} / \mathrm{L})$ were promptly corrected by intravenous fluid administration and electrolyte replacement through a central venous line (12 litters of normal saline with potassium and magnesium supplementation). A few hours after hospitalization, profuse watery mucoid diarrhea was observed, which continued for the next several days. During rehydration, the patient became severely polyuric; diabetes insipidus developed with an extremely high urine volume ( 9 liters/24h). The combination of hypokalemic state with normal blood pressure, low bicarbonate and very low urine potassium indicated extra-renal loss of potassium. Likewise, the hyponatremic state combined with low to normal blood pressure, dehydration and high BUN/creatinine ratio associated with low urine sodium also indicate extra-renal loss. Based on the above evidence of extra-renal loss together with the appearance of watery diarrhea, colonoscopy examination was performed. A massive spread tumor was detected in the recto-sigmoid colon; multiple biopsies demonstrated benign villous adenoma. On the seventh day after complete hemodynamic and electrolyte correction, the tumor was surgically removed by colectomy with primary anastomosis (Figure 1). The gross specimen showed a $14 \mathrm{x} 9 \mathrm{x} 7 \mathrm{~cm}$ giant tubulovillous adenoma with low grade dysplasia. Following the resection, the diarrhea resolved and blood tests showed normal renal function and electrolytes.

\section{Discussion}

Depletion syndrome is defined by villous adenoma of the colon associated with profuse watery diarrhea leading to serum electrolyte depletion, most often marked hyponatremia and hypokalemia and metabolic acidosis and is also known as McKittrick-Wheelock syndrome [1]. Villous adenoma of the colon should be suspected in patients with chronic diarrhea accompanied by weakness and fatigue and serum electrolyte depletion. Serum electrolyte imbalance was noted in $100 \%$ of cases. The stool loss of electrolyte is 10 to 40 times greater than normal. The definitive therapy is surgical resection of the tumor. The preoperative management of these patients must be very intensive and include intravenous fluid and electrolyte replacement under strict monitoring. If the electrolyte disturbance is corrected preoperatively, the postoperative course is usually good. 


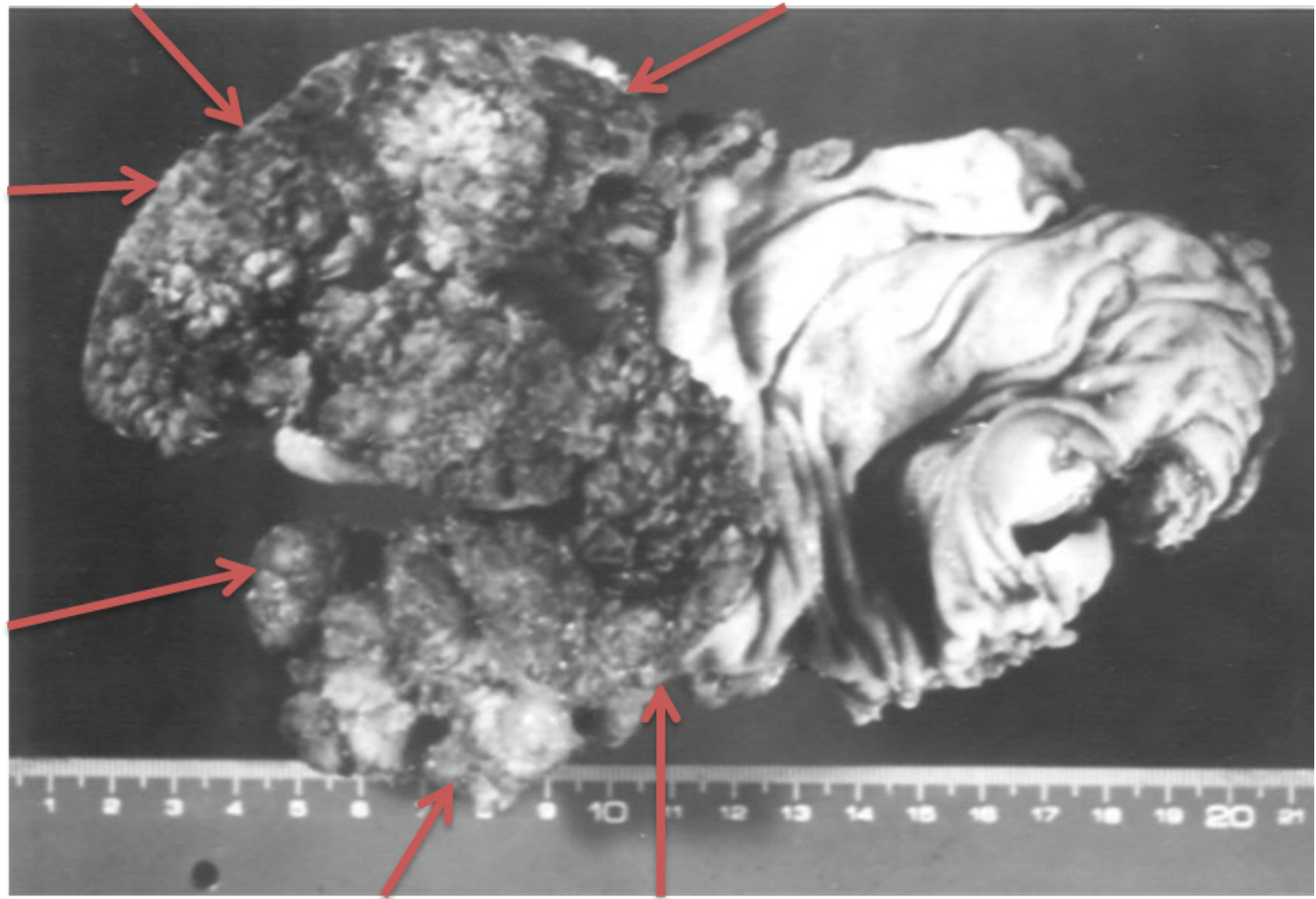

Figure 1: Giant tubulovillous adenoma of the colon, Note the large and broad rectal lesion; the red arrows are indicating the tumor borders; the scale is in centimeters

\begin{tabular}{|c|c|}
\hline Laboratory test on presentation & \\
\hline Hemoglobin & $16 \mathrm{~g} / \mathrm{dL}$ \\
\hline White cell count & $12.7 \times 10^{9} / \mathrm{L}$ \\
\hline Sodium & $106 \mathrm{mEq} / \mathrm{L}$ \\
\hline Potassium & $1.8 \mathrm{mEq} / \mathrm{L}$ \\
\hline Chloride & $62 \mathrm{mEq} / \mathrm{L}$ \\
\hline Blood urea nitrogen & $128 \mathrm{mg} / \mathrm{dL}$ \\
\hline Creatinine & $1.7 \mathrm{mg} / \mathrm{dL}$ \\
\hline Glucose & $130 \mathrm{mg} / \mathrm{dL}$ \\
\hline Magnesium & $0.9 \mathrm{mg} / \mathrm{dL}$ \\
\hline Calcium & $5.9 \mathrm{mg} / \mathrm{dL}$ \\
\hline $\mathrm{pH}$ & 7.46 \\
\hline $\mathrm{PcO}_{2}$ & 24 \\
\hline $\mathrm{Po}_{2}$ & 96 \\
\hline Bicarbonate & 17.5 \\
\hline Serum Osmolality & $270 \mathrm{mosmol} / \mathrm{L}$ \\
\hline Urine Osmolality & $330 \mathrm{mosmol} / \mathrm{L}$ \\
\hline Urinary Sodium & $5 \mathrm{mosmol} / \mathrm{L}$ \\
\hline Urinary Potassium & $4 \mathrm{mosmol} / \mathrm{L}$ \\
\hline
\end{tabular}

Table 1: Patient's Blood count and Biochemistry

There is evidence that supports the assumption that electrolyte elimination in this syndrome is an active process and results from tumor cell activity or the release of substances from those tumor cells. Duthie and Atwell [2] found that the intestine containing villous adenoma secreted water, sodium, and potassium, and that the net movement of sodium bore a direct relationship to the net movement of water. Steven et al [3] found that prostaglandin E1 (PGE1) levels in rectal content from patients with secretory villous adenoma were two to six times greater than the level in stool water of patients with infectious diarrhea. Treatment with indomethacin, a prostaglandin inhibitor, resulted in a gradual decrease in the volume of rectal discharge. Smelt et al [4] demonstrated that treatment with somatostatin analogue increased both the volume of secreted rectal fluid and the amount of PGE2 present in it, treatment with indomethacin decreased both. Jacob et al [5] showed increased adenylate cyclase, cyclic AMP, and cyclic AMP-dependent protein kinase ratio in the secretory tumor compared to non-secretory tumor or normal mucosa. 
It may be concluded that the net transfer of electrolytes and fluids in patients with secretory villous adenoma is an active process mediated by a humoral factor secreted from the tumor cells. This factor may be PGE or other agents that could lead to the irreversible activation of adenylate cyclase, resulting in increased cAMP production and profuse diarrhea [2-5]. The excessive rectal active loss of potassium leads to chronic hypokalaemia. The chronic hypokalaemia inhibits the normal compensatory mechanisms in electrolyte and water deprivation state and to the development of nephrogenic diabetes insipidus due to reduction in collecting duct responsiveness to vasopressin, mediated via decreased expression of aquaporin-2 [6,7].

Our patient presented with two unique problems. The hypomagnesemia $(0.9 \mathrm{mg} / \mathrm{dL})$ due to rectal loss of electrolytes reduces parathyroid hormone (PTH) secretion that led to severe hypocalcemia. The corrected hypomagnesemia raised back the PTH secretion that raised the calcium level without calcium administration. In addition, the patient had severe diabetes insipidus secondary to potassium depletion. Potassium depletion increases renal prostaglandin (PG) synthesis that induces nephrogenic diabetes insipidus and water loss [8]. Of interest, recently published case reports [9-11] did not describe hypomagnesemia or diabetes insipidus, despite presence of significant (as low as $2.6 \mathrm{mEq} / \mathrm{L}$ ) hypokalemia. Why hypomagnesemia and diabetes insipidus developed in our patient but not in others cannot be answered at this time.

\section{Conclusion}

In conclusion, villous adenoma cause a depleting syndrome characterized by de-hydratation, hyponatremia, hypokalemia and hypochloremia, Reversal of the biochemical derangement is the cornerstone of successful management. Once the patient is resuscitated, immediate surgical resection of the tumor is the treatment of choice.

\section{References}

1. McKittrick LS, Wheelock FC (1954) Carcinoma of the colon, Springfield publisher, IL, USA.

2. Duthie HL, Atwell JD (1963) The absorption of water, sodium, and potassium in the large intestine with particular reference to the effects of villous papillomas. Gut 41: 373-7.

3. Steven K, Lange P, Bukhave K, Rask-Madsen J (1981) Prostaglandin E2-mediated secretory diarrhea in villous adenoma of rectum: effect of treatment with indomethacin. Gastroenterology 80: 1562-6.

4. Smelt AH, Meinders AE, Hoekman K, Noort WA, Keirse MJ (1992) Secretory diarrhea in villous adenoma of rectum: effect of treatment with somatostatin and indomethacin. Prostaglandins 43: 567-72.

5. Jacob H, Schlondorff D, St Onge G, Bernstein LH (1985) Villous adenoma depletion syndrome. Evidence for a cyclic nucleotide-mediated diarrhea. Dig Dis Sci 30: 637-41.

6. Marples D, Frøkiaer J, Dørup J, Knepper MA, Nielsen S (1996) Hypokalemia-induced downregulation of aquaporin-2 water channel expression in rat kidney medulla and cortex. J Clin Invest 97: 1960-8.

7. Devuyst O (2012) Physiopathology and diagnosis of nephrogenic diabetes insipidus. Ann Endocrinol 73: 128-9.

8. Shah BR, Santucci K, Finberg L (1994) Magnesium deficiency as a cause of hypocalcemia in the CHARGE association. Arch Pediatr Adolesc Med 148: 486-9.

9. Khalife M, Eloubeidi MA, Hosn MA (2013) McKittrick-Wheelock syndrome presenting with dermatomyositis and rectal prolapsed. Clin Exp Gastroenterol 6: 85-9.

10. Hashash JG, Holder-Murray J, Aoun E, Yadav D (2013) The McKittrick-Wheelock syndrome: a rare cause of chronic diarrhoea. BMJ Case Rep 10.1136/bcr2013-009208.

11. Kure K, Kawai M, Ishiyama S, Kamiyama H, Tomiki Y, et al. (2015) Complete Endoscopic Submucosal Dissection of a Giant Rectal Villous Adenocarcinoma with Electrolyte Depletion Syndrome. Case Rep Gastroenterol 9: 126-31. 